\title{
A Educação para valores e as políticas públicas educacionais
}

口 Claudia Pradel*

घorge Alberto Torreão Dáu**

\section{Resumo}

A Constituição da República Federativa do Brasil, promulgada em 1988, estabelece como um dos objetivos fundamentais da República a construção de uma sociedade livre, justa e solidária, em que se promova o bem de todos, sem preconceitos ou discriminação. Em termos de política de educação, tal anseio é refletido quando, nos Parâmetros Curriculares Nacionais (PCN), escolhe-se a cidadania como "eixo vertebrador da educação escolar" (PARÂMETROS..., 2000, p. 25). Nesse sentido, elege-se a ética como um dos temas transversais a serem contemplados pelas instituições da educação básica. 0 desenvolvimento moral pode ser visto como uma das bases para a efetivação de um ensino inclusivo e que verdadeiramente promova os objetivos já citados, a partir do momento em que possibilita a percepção e a vivência das características multidimensionais que a educação idealmente deve ter. Assim, em um primeiro momento, deseja-se investigar de que forma a educação para valores, como instrumento para a construção de um ambiente social ético, está sendo vivida no espaço escolar atual. A partir dessa investigação, pretende-se oferecer pistas que permitam o desenvolvimento de um currículo que leve ao desenvolvimento da cidadania, através de uma integração entre o moral e o acadêmico. Deste modo, entende-se que o tema deve levar à apresentação de uma proposta de trabalho a ser desenvolvida sobre a questão específica da educação para valores, devidamente justificada e fundamentada.

Palavras-chave: Currículo. Educação. Escola. Valores. Inclusão.

\section{Moral Education and Public Educational Policies Abstract}

The Constitution of the Federative Republic of Brazil, promulgated in 1988, establishes as one of the Republic's fundamental goals to build a free, fair and

\footnotetext{
Especialista em Educação e Inclusão, Coordenação Central de Extensão (CCE), Pontifícia Universidade Católica (PUC-RIO); Professora do Ensino Fundamental (com inclusão), especializada em Atendimento Individual. E-mail: necapradel@ hotmail.com

.. Especialista em Educação e Inclusão, CCE, PUC-RIO; Mestre em Ciências em Engenharia Elétrica;

Coordenador do $8^{\circ}$ ano do Ensino Fundamental do Colégio Santo Inácio. E-mail: jdau@click21.com.br
} 
sympathetic society, that promotes everybody's well-being, without prejudice or discrimination. In terms of educational policy, this longing is reflected when, on the National Curricular Parameters (PCN), citizenship is elected as the "vertebral axis of school education" (PARÂMETROS..., 2000, p. 25). In this sense, ethic is elected as one of the so called transversal themes in basic education. Moral development can be seen as one of the building blocks to implement an inclusive education, that truly promotes the goals already mentioned, since it enables the perception and experience of the multidimensional characteristics that education ideally must have. So the authors begin with an investigation of the way an education in values, as a tool to build an ethical society, is really in course in school environment. This investigation intends to offer clues to create a curriculum which leads to the citizenship development, through an integration of both, moral and academic points of view. The authors believe that the theme must lead to the presentation of a work proposal to be developed on the specific issue of an education in values, duly justified and reasoned. Keywords: Curriculum. Education. School. Values and inclusion.

\section{Educación Moral Y Políticas Públicas de Educación \\ Resumen}

La Constitución de la Republica Federativa de Brasil, promulgada en 1988, establece como uno de los objetivos fundamentales de la Republica la construcción de una sociedad libre, justa y solidaria, que promueva el bienestar de todos, sin preconceptos o discriminación. En termos de política de educación, este deseo es reflejado en los Parámetros Nacionales de Educación (PCN), que eligen la ciudadanía como "el eje vertebral de la educación escolar" (PARÂMETROS..., 2000, p. 25). En esto sentido, la ética es elegida como unos de los temas transversales de la educación básica. La educación para valores puede ser vista como uno de los pilares de la implementación de una educación inclusiva, que leve a la atingir los objetivos citados, una vez que torna posible la percepción y la experiencia de las caracteristicas que la educación debe, idealmente, tener. De este modo, por primero se propone la investigación de como una educación para valores, como herramienta para la construcción de una sociedad ética, se produce verdaderamente en el ambiente escolar. Con base en esta investigación, se desea ofrecer pistas que posibiliten el desarrollo de un currículo que leve a la construcción de la ciudadanía, por la integración de los puntos de vista moral y académico. De este modo, percebe-se que este tema debe levar a la presentación de una propuesta de trabajo a ser desarrollada en la cuestión especifica de la educación para valores, correctamente justificada y motivada.

Palabras clave: Currículo. Educación. Escuela. Valores y inclusión. 


\section{Introdução}

0 estado atual da sociedade brasileira, em que se percebe uma melhoria das condições objetivas de vida da população, paralelamente a uma degradação das atitudes éticas que norteiam essa mesma população, não pode deixar de levar o educador a se preocupar diretamente com a formação para valores. Essa situação leva à convicção de que, independente da matéria lecionada, o educador deve buscar a conscientização dos alunos sobre a importância da ação individual e coletiva para a transformação da sociedade em um espaço de convivência, reconhecimento e respeito às diferenças.

Tal preocupação não está baseada apenas em convicções individuais, mas na própria Constituição da República Federativa do Brasil, promulgada em 1988, na qual constam como

[...] objetivos fundamentais da República: construir uma sociedade livre, justa e solidária; garantir o desenvolvimento nacional; erradicar a pobreza e a marginalização e reduzir as desigualdades sociais e regionais; promover o bem de todos, sem preconceitos de origem, raça, sexo, cor, idade e quaisquer outras formas de discriminação (art. $3^{\circ}$ da Constituição Federal) (PARÂMETROS..., 2000, p.19).

A partir daí elegeu-se "a cidadania como eixo vertebrador da educação escolar, o que implica colocar-se explicitamente contra valores e práticas sociais que desrespeitem aqueles princípios, comprometendo-se com as perspectivas e decisões que os favoreçam" (PARÂMETROS..., 2000, p. 25).

E esta cidadania tem na educação uma parceira importante para seu desenvolvimento, em particular no tema transversal da ética, que

[...] interroga sobre a legitimidade de práticas e valores consagrados pela tradição e pelo costume. Abrange tanto a crítica das relações entre os grupos, dos grupos nas instituições e perante elas, quanto à dimensão das ações pessoais. Trata-se portanto de discutir o sentido ético da convivência humana nas suas relações com várias dimensões da vida social (PARÂMETROS..., 2000, p. 30).

Também a Organização das Nações Unidas para a Educação, a Ciência e a Cultura (UNESCO), propõe a criação de um mundo melhor através da educação:

Num mundo compartilhado, porém intensamente competitivo, temos de descobrir maneiras pelas quais os diferentes grupos culturais possam conviver, respeitar a dignidade e o valor de cada pessoa e de cada cultura, e aprender a compartilhar e a cuidar de nosso futuro comum (POWER, 2002, p. 42).

Ensaio: aval. pol. públ. Educ., Rio de Janeiro, v. 17, n. 64, p. 521-548, jul./set. 2009 
E, levando em conta um ambiente essencialmente plural, ressalta a busca de valores comuns que possibilitem a convivência:

0 Relatório da Comissão Mundial para a Cultura e o Desenvolvimento da UNESCO (1995b) define esses valores fundamentais como uma 'ética global', e vê os princípios da democracia, da paz, dos direitos humanos e do pluralismo como seus ingredientes básicos. Mas, simultaneamente, nossa ética global dá ênfase ao respeito pela dignidade e pelo valor de cada indivíduo e de cada cultura (POWER, 2002, p. 43).

Trata-se de processo de diálogo, a partir da busca empírica por valores consensuais, centrada nos direitos humanos, reconhecendo e lembrando-se de que estes são fruto de uma ideia relativamente recente, com cerca de 50 anos. Um desses direitos é a educação, com "consenso geral de que a preocupação para com o outro, a responsabilidade, a civilidade, a tolerância e o respeito pelo outro sejam valores importantes, que devem ser promovidos" (POWER, 2002, p. 45). Assim, a educação básica seria uma condição para a democracia participativa, pois, "ao concordar em tomar como meta tanto a unidade global quanto a diversidade individual e cultural, os educadores assumiram uma tarefa muito mais árdua do que qualquer coisa já antes tentada" (POWER, 2002, p. 48), uma vez que se contrapõe ao habitual para grupos (políticos, econômicos, religiosos [...]) dominantes.

Uma educação que leve ao respeito e à tolerância, portanto, deve buscar a promoção de "cidadanias múltiplas" (POWER, 2002, p. 51-52) pelo conhecimento, a compreensão e o respeito por outras culturas, com "ênfase renovada nas dimensões morais e culturais da educação".

0 caráter eminentemente prático da questão sugere que esta reflexão não se restrinja a ser um estudo teórico, mas que resulte em um produto concreto, que se reflita no desenvolvimento de bases para uma aplicação curricular sobre a questão dos valores. Para atingir o objetivo proposto, foram percorridas as seguintes linhas gerais de estudo:

- Valores, moral, ética e sociedade: qual a relação entre os mesmos e qual o papel da organização de grupos sociais e do relacionamento humano para a questão?

- Qual a relação entre escola e modelo de sociedade?

- Qual o papel da educação na formação de valores: a escola é espaço para isso? Sozinha? Com a família? Com a sociedade como um todo?

- 0 que se entende por currículo? 0 que se espera da construção de uma base curricular?

- Como trabalhar valores na escola? Como tema transversal? Através de conteúdos? Como um processo constante de diagnóstico e adaptação curricular a partir desse diagnóstico? Qual o ponto de partida? Qual o papel da formação dos profissionais para o sucesso desse trabalho?

Ensaio: aval. pol. públ. Educ., Rio de Janeiro, v. 17, n. 64, p. 521-548, jul./set. 2009 


\section{Educação para valores na escola}

No Brasil, os Parâmetros Curriculares Nacionais (PCN) "constituem um referencial de qualidade para a educação no Ensino Fundamental em todo o País" (PARÂMETROS..., 1997, p. 13). Neles, a formação para valores é sugerida a partir da apresentação dos temas transversais. "O tema do documento de ética, portanto, não é novo, mas é novo ter um documento que possibilite abrir discussões sobre este assunto no contexto escolar" (PARÂMETROS..., 2000, p. 65).

Os PCN apresentam historicamente os referenciais dos valores, orientando os princípios de exercício da cidadania em busca de uma escola que forme cidadãos de contextos diversos. 0 tema da ética é importantíssimo para o homem que vive em sociedade, pois exige que este saiba relacionar-se, sugerindo, então, o tema central desse estudo, os valores, que são também o foco de estudo da moral e da ética. Por valores se quer tratar da questão dos valores morais. Estes podem ser entendidos a partir da noção filosófica de que valor é tudo o que é bom, útil e positivo, mas, em termos morais, revestem-se de um aspecto cultural e coletivo, que vai fundamentar as normas e regras que prescrevem a conduta correta.

Oriunda da Constituição, a referência brasileira de comportamento moral advém do convívio social e, desse modo, a preocupação é referir-se ao perfil democrático da sociedade brasileira, considerando o caráter abstrato dos valores. Complementar a essa visão, a ética vem equilibrar as relações a partir do pensar, do refletir e do construir nos diversos espaços.

De acordo com os PCN, é fundamental para a escola que seja legitimada a presença de valores e regras morais na conduta dos alunos, professores e demais integrantes, independentemente do que apareça na esfera pública, para formar integralmente um cidadão.

A educação moral deve ser pautada em dois pilares: a afetividade e a racionalidade. A afetividade envolve o que se chama de "projeto de felicidade", enquanto a racionalidade se caracteriza pela elevação do indivíduo a responsável pelas escolhas feitas, sendo livre para agir e consciente das consequências de seus atos. "Tanto a afetividade como a racionalidade desenvolvem-se a partir das interações sociais, desde a infância e durante a vida toda. Como representam a base moral, esta também se desenvolve" (PARÂMETROS..., 2000, p. 83).

\section{Tendências da educação}

Mesmo para um tema que se denomina como transversal, é necessário que seja refletido em uma base curricular, neste caso voltada ao trabalho com valores e, portanto, ligada à formação humanista, que conjuga conhecimento e pensamento

Ensaio: aval. pol. públ. Educ., Rio de Janeiro, v. 17, n. 64, p. 521-548, jul./set. 2009 
ético, refletido em ações. 0 modo de implementação dessa base curricular é categorizado, nos PCN, pelas tendências presentes nas experiências educacionais brasileiras, a saber:

- Filosófica;

- Cognitivista;

- Afetiva;

- Moralista;

- Democrática.

A partir das diversas experiências, não parece haver uma tendência melhor que outra, e sim situações nas quais as mesmas mostram-se mais ou menos eficientes. No contexto presente, entretanto, as tendências filosófica, cognitivista e afetiva abrangem o que se acredita ser o melhor referencial para a formação de um cidadão provido de princípios éticos e de valores morais.

A tendência filosófica origina-se dos antigos gregos e se propõe a apresentar várias opções diante de uma situação, para que os indivíduos as conheçam e possam refletir sobre as mesmas, antes de agir.

Na tendência cognitivista, é dada importância "ao raciocínio e à reflexão sobre questões morais, e também a não apresentação de um elenco de valores a serem 'aprendidos' pelos alunos" (PARÂMETROS..., 2000, p. 89).

Já na tendência afetiva, procura-se: fazer os alunos encontrarem seu equilibrio pessoal e suas possibilidades de crescimento intelectual mediante técnicas psicológicas. Procura-se fazer com que cada um tome consciência de suas orientações afetivas concretas, na esperança de que, de bem consigo mesmo, possa conviver de forma harmoniosa com seus semelhantes (PARÂMETROS..., 2000, p. 90).

\section{Vertente acadêmica e vertente moral}

Além da tendência que predomina em um determinado ambiente escolar, é importante perceber como a questão dos valores é trabalhada na escola. Embora exista "um amplo consenso de que... não se trata de introduzir uma disciplina específica sobre direitos humanos" (CANDAU, 2003, p. 98), discute-se se o mais adequado é introduzi-los através de uma abordagem interdisciplinar (por temas geradores) ou transversalmente. Nos PCN, sugere-se um trabalho com base na transversalidade. Tal escolha se faz a partir do reconhecimento da escola como o espaço social do conflito, da reflexão, da construção e da troca. Sendo assim, a escola é o local em que a transversalidade está presente a todo instante e é nela, por definição, que as relações pautadas em valores devem ser estabelecidas e o currículo "é a questão que diz respeito àquilo que a escola faz e para quem faz ou deixa de fazer" (BERTICELLI, 2005, p. 160). 0 que se percebe, entretanto, é que essa transversalidade assume

Ensaio: aval. pol. públ. Educ., Rio de Janeiro, v. 17, n. 64, p. 521-548, jul./set. 2009 
diversos aspectos. Nesse sentido, é importante estabelecer uma relação entre a vertente acadêmica e a vertente da educação moral no modo de construção do ambiente escolar. Para tanto, utiliza-se a definição apresentada por Stengel e Tom (2006), que categoriza essa relação em função do tipo de interface existente entre ambas, como na Tabela 1 a seguir (STENGEL; TOM, 2006, p. 38), adaptada e da qual foi retirada a coluna referente a exemplos, por não se referirem a instituições brasileiras:

Tabela 1 - As categorias de relacionamento entre educação moral e acadêmica.

\begin{tabular}{|c|c|c|c|c|}
\hline Categoria & Definição & $\begin{array}{l}\text { Grau de conexão } \\
\text { entre acadêmico } \\
\text { e moral }\end{array}$ & $\begin{array}{l}\text { Natureza da } \\
\text { relação entre } \\
\text { acadêmico e } \\
\text { moral }\end{array}$ & $\begin{array}{l}\text { Força motriz } \\
\text { (acadêmico ou } \\
\text { moral como } \\
\text { chave para a } \\
\text { ação) }\end{array}$ \\
\hline Separada & $\begin{array}{l}\text { Sem interface } \\
\text { entre moral e } \\
\text { acadêmico }\end{array}$ & Nenhum & $\begin{array}{l}\text { Domínios } \\
\text { discretos }\end{array}$ & Independente \\
\hline Sequencial & $\begin{array}{l}\text { Moral precede } \\
\text { acadêmico ou } \\
\text { vice-versa }\end{array}$ & Fraco & $\begin{array}{l}\text { Ligados } \\
\text { sequencialmente }\end{array}$ & $\begin{array}{l}\text { Depende da } \\
\text { precedência }\end{array}$ \\
\hline Dominante & $\begin{array}{l}\text { Moral domina } \\
\text { acadêmico ou } \\
\text { vice-versa }\end{array}$ & Fraco & $\begin{array}{l}\text { Ligados } \\
\text { fortemente }\end{array}$ & $\begin{array}{l}\text { Depende da } \\
\text { dominância }\end{array}$ \\
\hline Transformadora & $\begin{array}{l}\text { Moral } \\
\text { transforma } \\
\text { acadêmico ou } \\
\text { vice-versa }\end{array}$ & Estreito & $\begin{array}{l}\text { Mesclados } \\
\text { fortemente } \\
\text { de modo } \\
\text { sequencial }\end{array}$ & $\begin{array}{l}\text { Depende de } \\
\text { quem é a força } \\
\text { transformadora }\end{array}$ \\
\hline Integrada & $\begin{array}{l}\text { Moral e } \\
\text { acadêmico } \\
\text { transformam-se } \\
\text { mutuamente }\end{array}$ & Estreito & $\begin{array}{l}\text { Mesclados } \\
\text { fortemente }\end{array}$ & Dialética \\
\hline
\end{tabular}

Fonte: Adaptada de Stengel e Tom (2006).

Parece interessante apresentar alguns esclarecimentos sobre as referidas categorias. Estas não representam uma sequência evolutiva, mas diferentes modos de se encarar um ambiente escolar. Além disso, a relação entre acadêmico e moral, em cada uma das categorias da Tabela 1, merece especial atenção:

- Quando acadêmico e moral são vistos de forma separada, considera-se que o aprendizado é a soma de objetivos totalmente distintos;

- Na categoria sequencial, os autores observam que o cenário mais comum é de uma precedência do moral em relação ao acadêmico (STENGEL; TOM, 2006, p. 39);

- Na categoria dominante, a principal diferença em relação à sequencial é que há uma subordinação entre o aprendizado moral e o acadêmico; 
- Na categoria transformadora, o movimento do aprendizado ocorre apenas em uma direção, isto é, é iniciado por um dos tipos de aprendizado e imposto ao outro;

- Por fim, a categoria integrada não permite distinguir claramente entre o que é aprendizado moral e acadêmico. Ambos se reforçam e se complementam.

A questão que se coloca, então, é buscar identificar qual ou quais desses tipos de relacionamentos são mais prevalentes nas escolas e como trabalhar a questão dos valores em cada categoria. 0 condicionante do acesso à universidade, refletido na importância dada aos exames vestibulares atuais, sugere que três modelos predominem: o separado, o sequencial (com precedência do acadêmico) e o dominante (com dominância do acadêmico). Destes, os dois primeiros parecem permitir a implantação do trabalho com ética, através de temas transversais, preconizado pelos PCN. Já o terceiro, subordinará qualquer trabalho sobre a questão dos valores à obtenção de resultados acadêmicos, possivelmente relegando-o a um estágio secundário e desvalorizado.

0 modelo separado, sem negar a importância da educação para valores, trata ambas as esferas como completamente desconectadas, o que dificulta, mas não inviabiliza a utilização de temas transversais para o trabalho com valores. Parece ser este o modelo das tradicionais escolas religiosas, em que:

Valores tradicionais são expressos sob a forma comportamental de virtudes, e virtudes são frequentemente ensinadas sob a forma de instrução direta. De fato, a educação do caráter é algumas vezes ensinada como se fosse uma matéria escolar por si (STENGEL; TOM, 2006, p. 45).

\section{Projeto de escola}

Com essas questões e limitações em mente, cabe também lançar um olhar sobre o modo como os PCN referem-se à questão da ética. Como não podia deixar de ser, por tratar-se de um documento que indica temas, objetivos e indicadores para um ambiente muito diversificado, apresentam apenas caminhos genéricos. Não consideram - e nem poderiam considerar - condições e questões específicas de um determinado ambiente social, cultural e escolar. Dão-se - poder-se-ia dizer - "pistas" para a definição de diretrizes curriculares e de trabalho, a serem refletidas na organização do dia a dia escolar. Este dia a dia, aliás, deveria refletir seu Projeto Político-Pedagógico, entendido como um processo de mudança e de antecipação do futuro, que estabelece princípios, diretrizes e propostas de ação para melhor organizar, sistematizar e significar as atividades desenvolvidas pela escola como um todo. Sua dimensão políticopedagógica pressupõe uma construção participativa que envolve ativamente os diversos segmentos escolares, de modo a promover a transformação necessária e desejada pelo coletivo escolar e comunitário. 
Todo esse processo, porém, não pode representar apenas uma formalidade a ser cumprida. É preciso viabilizar as condições necessárias não apenas para construí-lo, mas, sobretudo, para executá-lo, sem esquecer-se do acompanhamento, avaliação e reconstrução. Neste sentido, percebe-se como necessária a instituição de um tempo próprio para que se efetue um diagnóstico contínuo das necessidades do ambiente escolar, bem como a instauração de uma cultura de participação nas escolas.

Essa cultura de participação vai de encontro a diversas práticas correntes nas escolas atuais, em que se levam em conta, sobretudo, os resultados estatísticos, deixando em segundo plano a plena realização do educando. 0 foco no aprendizado acadêmico, sem que este seja equilibrado pela busca da autorrealização do aluno, pode conduzir a distorções em que critérios de avaliação exclusivamente quantitativos gerem uma postura reativa e opressora. Parece haver a necessidade do emprego concomitante de métodos quantitativos e qualitativos, que considerem o desenvolvimento humano como um todo e não apenas intelectual. É preciso que este desenvolvimento englobe as demais dimensões constitutivas da pessoa humana: moral, espiritual, afetiva [...]. Ou seja, o que se deseja é que cada indivíduo consiga passar de forma plena e saudável da etapa da moral heterônoma para a da moral autônoma, conforme Piaget (DIAZ-AGUADO; MEDRANO, 1999, p. 22), ou pelos diferentes níveis ou estágios do desenvolvimento moral, segundo Kohlberg (apud DIAZ-AGUADO; MEDRANO, 1999, p. 27).

\section{As etapas do desenvolvimento segundo Piaget e Kohberg}

Pode-se distinguir, conforme Piaget, duas formas distintas de moral. Precedidas por uma fase de anomia, em que as crianças sabem que as coisas são feitas, mas não identificam a norma, as formas distintas de moral são:

- Heterônoma, em que as crianças obedecem às normas por amor e medo da autoridade (norma externa);

- Autônoma, em que as normas são internalizadas, tornando possível aos indivíduos, por si mesmos, escolher entre o certo e o errado.

Lawrence Kohlberg (apud DIAZ-AGUADO; MEDRANO, 1999, p. 28), em seus estudos, estabeleceu um modelo cognitivo-evolutivo, estendendo o modelo de Piaget, e que postula

Que as principais mudanças produzidas com o desenvolvimento supõem importantes reestruturações no significado que o sujeito dá ao mundo (hipótese cognitiva), e que 0 resultado das mesmas possibilita formas superiores de adaptação a tal mundo (hipótese evolutiva).

A descrição do desenvolvimento moral proposta por Kohlberg, apresentada na Tabela 2, supõe três níveis: pré-convencional, essencialmente heterônomo, em que o indivíduo se orienta pelas consequências imediatas de seus atos, com uma pers-

Ensaio: aval. pol. públ. Educ., Rio de Janeiro, v. 17, n. 64, p. 521-548, jul./set. 2009 
pectiva de regras externas ao eu; o convencional, em que o indivíduo se percebe membro de uma sociedade e se orienta em função das expectativas dos demais ou da manutenção do sistema social, ou seja, ainda com uma moral heterônoma, embora mais avançada no modo como se estabelece essa relação com o externo; e o pós-convencional, autônomo, que se orienta "para a construção de princípios morais autônomos que permitirão chegar a uma sociedade ideal" (DIAZ-AGUADO; MEDRANO, 1999, p. 29). Por fim, cada um desses níveis é dividido em dois estágios, cuja descrição não cabe discutir aqui.

Tabela 2 - Os seis estágios de juízo moral descritos por Kohlberg (subdivisões dos três níveis de juizo moral).

\begin{tabular}{c|l}
\hline Nivel & Estágio heterônomo (1) \\
Pré-Convencional & Estágio hedonista-instrumental do intercâmbio (2) \\
\hline $\begin{array}{c}\text { Nível } \\
\text { Convencional }\end{array}$ & $\begin{array}{l}\text { Estágio da conformidade com as expectativas e relações interpessoais (3) } \\
\text { Estágio do sistema social e da consciência (4) }\end{array}$ \\
\hline $\begin{array}{c}\text { Nivel } \\
\text { dosPrincípios }\end{array}$ & $\begin{array}{l}\text { Estágio do contrato social, da utilidade e dos direitos do individuo (5) } \\
\text { Estágio dos princípios éticos universais (6) - hipotético }\end{array}$ \\
\hline
\end{tabular}

Fonte: Adaptado de Kohlberg citado por Diaz-Aguado e Medrano (1999).

Nesse sentido, a afetividade parece ser o elemento de ligação entre as diversas esferas da aprendizagem, mesmo porque a evolução do nível convencional para os seguintes, de acordo com a classificação estabelecida por Kohlberg (Tabela 2), passa pela existência de uma motivação interna, relacionada à aprovação geral, à lealdade às pessoas e grupos e ao bem-estar dos indivíduos e da sociedade.

Ao olhar para os eixos norteadores de cada uma dessas etapas, podem-se perceber as regras (o que deve ser feito), características da fase de anomia, os princípios (a matriz das regras), que caracterizam a fase da heteronomia e os valores (o motivo dos princípios), levando à autonomia. Assim, à medida que ocorre o desenvolvimento moral, mais elevado é o eixo que norteia o indivíduo.

\section{Valores sim, mas quais?}

Os valores são, portanto, aquilo que caracteriza o estágio da autonomia do desenvolvimento da pessoa humana.

Do ponto de vista ético, os valores são os fundamentos da moral, das normas e regras que prescrevem a conduta correta. No entanto, a própria definição desses valores varia em diferentes doutrinas filosóficas. Para algumas concepções, é um valor tudo aquilo que traz a felicidade do homem [...]. Alguns filósofos consideram também que os valores se caracterizam por relação aos fins que se pretendem 
obter, a partir dos quais algo se define como bom ou mau. Outros defendem a ideia de que algo é um valor em si mesmo (JAPIASSÚ; MARCONDES, 1996, p. 268).

A associação de valor e felicidade remonta a Aristóteles, que considera que para ser feliz o homem deve praticar a virtude e a retidão.

A construção de valores, de acordo com Piaget, é função de uma troca afetiva e da interação com o mundo a partir de uma relação ativa, e não uma simples internalização "sofrida por sujeitos 'passivos', moldados pela sociedade, pela cultura e pelo meio em que eles vivem" (ARAÚJ0, 2007, p. 20).

Em termos modernos, muitos estudiosos buscam um equilibrio entre valores individuais e sociais. Por exemplo, Adela Cortina (apud ANDRADE, 2006, p. 244), propõe uma ética civil, que seria um ponto de articulação entre mínimos de justiça - o que se pode exigir - e máximos de felicidade - a qual se deve convidar. Essa ética seria capaz de articular a universalidade dos valores morais com a pluralidade de ofertas de valores éticos particulares, consolidando o que se entende por vida digna e os diferentes projetos de vida feliz.

Para atingir o objetivo de estabelecer esses mínimos de justiça, torna-se necessário abrir um diálogo entre as culturas, de modo que se atinja uma base coincidente entre os códigos morais. Esses mínimos seriam exigiveis de todos os códigos morais, ou seja, nenhum código moral poderia estar abaixo deles. Tal conceito é corroborado pelos PCN, que citam um

Núcleo moral de uma sociedade, ou seja, valores eleitos como necessários ao convívio entre os membros [dessa] sociedade. A partir deles, nega-se qualquer perspectiva de 'relativismo moral'. [...] Trata-se de um consenso mínimo, de um conjunto central de valores, indispensável à sociedade democrática (PARÂMETROS..., 2000, p. 71).

Ao se compararem os valores mínimos propostos por Marcelo Andrade (2006) com o conteúdo mínimo proposto nos PCN a ser trabalhado como conteúdo de Ética, é possivel perceber grande coincidência entre os mesmos, como pode ser visto a seguir:

- Igualdade que, nos PCN, pode ser relacionada à justiça;

- Tolerância, que, do mesmo modo, pode ser relacionada ao respeito mútuo;

- Diálogo, presente em ambos;

- Liberdade, que não está presente nos PCN;

- Solidariedade, presente apenas nos PCN.

Em relação à solidariedade, entretanto, pode-se considerar que "o bom não pode ser exigido dos outros seres racionais, pois se trata fundamentalmente de uma realização subjetiva, pessoal e intransferível" (ANDRADE, 2006, p. 245). 
Em relação aos máximos de felicidade, estes se enquadram "no caráter abstrato dos valores abordados. Ética trata de princípios e não de mandamentos [...]. É preciso, portanto, ter claro que não existem normas acabadas, regras definitivamente consagradas. A ética é um eterno pensar, refletir, construir" (PARÂMETROS..., 2000, p. 72).

Novamente tomando como referência o modelo de Kohlberg (apud DIAZ-AGUADO; MEDRANO, 1999, p. 80), tais máximos parecem estar associados aos estágios ou niveis a partir do terceiro - moralidade da normativa interpessoal - já que "é muito importante 'ser bom' e isso significa ter boas intenções, mostrando consideração para com os outros, antepondo as expectativas e sentimentos dos demais aos próprios interesses". Esse estágio, entretanto, ainda é pouco elaborado, aperfeiçoando-se e complementando-se nos subsequentes.

Embora pareça difícil encontrar pontos comuns no que se refere a uma definição de bem, percebe-se que, de modo geral, não é assim. As grandes religiões, em seu ideário, constituem-se em "éticas de felicidade [que] pretendem oferecer ideais de uma vida digna e boa" (ANDRADE, 2006, p. 245), e esses ideais muitas vezes coincidem entre si. Quer sejam religiões, quer sejam filosofias de vida, Cristianismo, Judaísmo, Islamismo, Hinduísmo, Budismo, Confucionismo [...], possuem um núcleo comum de "convites" muito mais amplo que os mínimos propostos já vistos.

Andrade (2006, p. 254), em seu artigo já citado, afirma que

Uma agenda ética mínima para uma educação intercultural não é um convite a projetos de máximos felicitantes, mas exigência moral irrenunciável. E, para se educar numa exigência moral [...] uma proposta educativa não pode renunciar à sua missão de educar em mínimos de justiça que são imprescindíveis para se manter o próprio pluralismo que tanto se deseja.

Ele afirma, portanto, que a educação em mínimos de justiça é necessária ao pluralismo e ao acolhimento da diversidade. A inclusão nos PCN da solidariedade como pertencendo ao mínimo exigivel parece indicar a necessidade de um esforço educativo de levar o indivíduo a garantir um mínimo para buscar o máximo em termos de comportamento ético e o reflexo do mesmo na sociedade.

A solidariedade poderia contrabalançar

[...] a tendência à separação e ao isolamento entre pessoas, para se recuperar do excesso do individualismo que valora tudo em função do interesse próprio, para abandonar as imagens do outro que o representam como um objeto e que convidam a usá-lo como se faz com todos os demais objetos (PUIG, 2007, p. 70).

Ensaio: aval. pol. públ. Educ., Rio de Janeiro, v. 17, n. 64, p. 521-548, jul./set. 2009 
Assim, no sentido de acolher e aceitar o outro em sua dignidade de ser humano independente de características e escolhas, Puig (2007, p. 70-71) propõe que é necessário aprender a conviver, sair do egocentrismo dos seres humanos, reforçando o altruísmo, estabelecendose "vínculos pessoais baseados na abertura e na compreensão", e descobrir o outro de modo a tratá-lo humanamente, colocando-se no lugar dele e compreendendo-o "a partir de dentro". Esse aprender a conviver supõe o engajamento com projetos comuns.

Em um mundo globalizado, que se defronta com uma visão ao mesmo tempo uniforme e multifacetada, perceber o conteúdo, ou melhor, a existência da ética perpassando toda a sociedade, leva à necessidade da implementação de uma proposta de transversalidade que ajude "o aluno a não dividir a moral num duplo sistema de valores, aqueles que se falam e aqueles que, de fato, inspiram as ações" (PARÂMETROS..., 2000, p. 95). Mas, ao contrário do que é preconizado nos PCN, que sugerem "não refazer o erro da má experiência da Moral e Cívica", alguns autores acreditam que a proposta de transversalidade deva ser complementada por outra, a exemplo do que está sendo feito na Espanha, que inseriu

[...] no currículo escolar a disciplina de Educação Cidadã [...] [Afinal], como tornar melhor uma nação sem um povo dotado de consciência cidadã e empenhado no aprimoramento da democracia? [...] A raiz da ética é a educação. Resta saber se a educação quer formar cidadãos ou consumistas, pessoas integras ou apenas mão de obra qualificada para o mercado de trabalho (BETTO, 2007).

De qualquer modo, não é possível negar o papel da educação na construção dos valores de uma sociedade. Tal educação, entretanto

[...] sob pena de condenar a si própria à irrelevância, [...] terá de contribuir para a resolução daquele que parece ser o mais premente dos desafios enfrentados pela humanidade - alcançar a unidade e, simultaneamente, reter, respeitar, valorizar e incentivar a diversidade (CAMPBELL, 2002, p. 21).

\section{Mudando o paradigma}

Como dito anteriormente, a escola atual depende muito, para a avaliação do desenvolvimento de seus alunos, da utilização de métodos quantitativos, quando o ideal seria mesclar estes métodos com outros, qualitativos. Ao olhar para o educando sob uma visão qualitativa, está-se ressaltando o papel do profissional de educação, que deve ter um olhar personalizado de modo a oferecer a cada aluno a oportunidade para autorrealização, não mais estabelecendo metas e objetivos uniformes, mas fazendo-o de forma a acomodar todos os alunos nas suas diferenças e potencialidades. Para tal, é preciso reconhecer as diversas instâncias de apoio que fazem parte de uma estrutura sistêmica interdisciplinar que integra,

Ensaio: aval. pol. públ. Educ., Rio de Janeiro, v. 17, n. 64, p. 521-548, jul./set. 2009 
na prática, quatro áreas de conhecimento: a fonoaudiologia; a psicologia; a pedagogia; e a saúde e nutrição. A estas, soma-se o apoio de uma estrutura de serviço social. Tais instâncias, se funcionarem como áreas estanques, perderão boa parte de sua efetividade. É preciso que se integrem para melhor servir ao alunado. $E$, para tal, é preciso que se conheçam, tanto no que se refere a escopo de atuação, mas também em relação a suas especificidades. Assim, são necessárias reuniões de planejamento integrado, bem como um plano de formação continuada, não com a intenção de transformar cada profissional em um especialista "em tudo", mas de permitir que este seja capaz de reconhecer a necessidade de recorrer a outras especialidades e como melhor fazê-lo.

Outro ponto importante para o aprendizado moral é a questão da metodologia. Muitas vezes a escola aparenta não ser uma instituição única, mas um conjunto de instituições agrupadas em uma única estrutura física. Claramente divide-se em quatro segmentos, que podem estar mais ou menos integrados entre si, ou mesmo apenas sequenciados sem afinidades perceptíveis. São eles: Educação Infantil; Ensino Fundamental I ( $1^{\circ}$ a $5^{\circ}$ ano, divididos em dois ciclos); Ensino Fundamental II ( $6^{\circ}$ a $9^{\circ}$ ano, divididos em dois ciclos); e Ensino Médio. Verifica-se, inclusive, que algumas escolas organizam as séries terminais de modo a incluir o $9^{\circ}$ ano na mesma estrutura de gestão do Ensino Médio. Em cada um desses segmentos mudam - ou podem mudar - as condutas, as cobranças - em intensidade e modo - e a postura dos professores em relação ao aluno. A própria quantidade de professores regentes - um nas séries iniciais, passando a dois a partir do $4^{\circ}$ ano e chegando a uma dezena no Ensino Médio - ainda ocorre de forma brusca em alguns casos. E o volume de conteúdo cresce, juntamente com o nível de exigência, à medida que se aproxima o "fantasma" do ingresso na universidade. Assim, os professores sentem-se mais pressionados a privilegiar a matéria, e menos a dar atenção ao desenvolvimento integral do aluno, inclusive no que se refere à educação para valores.

Tão relevante quanto os anteriores é a disparidade existente entre os sistemas de ensino público e privado, em que os profissionais agem e reagem em desacordo com as responsabilidades do que se deseja promover com o ato de educar.

A escola pública, de modo geral, caracteriza-se pela ausência de qualidade, baixa valorização dos profissionais, baixas condições de resgatar o alunado, além de não se adequar às políticas e práticas educativas vigentes.

A escola particular por sua vez, caminha entre o tênue limiar de instituição de ensino e empresa com fins lucrativos e responsabilidades fiscais. Nesse ambiente, no entanto, ainda é perceptível um cuidado maior dos profissionais de escolas e das próprias famílias a eles relacionadas com a formação de cidadãos. 
Muitas dessas instituições possuem porte pequeno ou médio e atendem a nichos de mercado que não são atingidos pelas grandes franquias educacionais. Estas franquias - dentre elas os famosos "cursinhos" ou as deles derivadas - diferenciam-se justamente por focar-se quase que exclusivamente nos resultados acadêmicos obtidos. De qualquer modo, muitas vezes a preocupação com a educação para valores parece estar depositada exclusivamente na ação da escola, sem uma efetiva parceria com e por parte das familias. Parece haver uma participação mais efetiva dos pais da Educação Infantil e séries iniciais do Ensino Fundamental ( $1{ }^{\circ}$ ciclo), participação essa que se torna cada vez menos perceptivel na postura dos pais de alunos do Ensino Fundamental II e Ensino Médio. Há dois aspectos sobre essa questão. 0 primeiro, é que muitas vezes não se reconhece que familia e escola são dois contextos diferentes e diversificados, com similaridades e diferenças, que se acentuam em uma sociedade que, cada vez mais, apresenta caracteristicas plurais. 0 segundo reflete as mudanças cada vez mais rápidas ocorridas na sociedade contemporânea que levam, muitas vezes, a novos significados para o papel da família. Esta, de fonte de valores e espaço de autoridade, passa a ser provedora de bens de consumo. Nesse contexto,

a sociedade de consumo e o imaginário em que estamos submersos, nos dizem que os objetos desejados, anteriormente vistos como supérfluos são, na verdade, essenciais para o nosso bem-estar e felicidade. É aí que a autoridade aparece como uma ideia anacrônica, como veículo de restrições insuportáveis: em termos de relação entre pais e filhos, consideramos mais pertinente falar de uma recodificação de valores (Ariès, 1981 e Géllis, 1991, apud) cujo instrumento mais pertinente parece ser a própria sociedade de consumo (CALDANA, 1998).

Percebe-se, adicionalmente, que:

A autoridade familiar como primeira forma de respeito a uma instância ligada à tradição vem sendo questionada. $A$ reestruturação familiar - consequência da reorganização dos papéis - é responsável por um período de redefinição das posições de autoridade. 0 modelo familiar, já há algumas décadas, vive transformações graduais, mas extremamente profundas, dado que a inserção da mulher no mercado de trabalho e o aumento dos níveis de separação de casais contribuem para a emersão de um novo padrão de convivência e referências identitárias (SETTON, 2002).

Esse novo padrão de convivência, que inclui casais separados e recasados, provavelmente se acentua quando o aluno se encontra em séries mais avançadas, o que poderia explicar uma possível queda de participação dos pais na parceria com a escola em séries mais adiantadas.

Ensaio: aval. pol. públ. Educ., Rio de Janeiro, v. 17, n. 64, p. 521-548, jul./set. 2009 
Comparando a escola pública à particular, é preciso ater-se não apenas às condições econômicas, mas a mudanças no perfil de formação da sociedade. Esta mudança ocorre a uma velocidade e com um grau de demanda maior que a possibilidade da ação dos agentes públicos, cerceada pela máquina burocrática e sistêmica que conduz nosso país. Essa ação não é desnecessária, mas precisaria responder de modo mais eficiente às necessidades do presente e não do passado distante, tornando mais atual e efetiva a prática no espaço escolar, a formação dos profissionais atuantes, a integração entre as diferentes esferas educacionais e a sociedade em que estes atuarão em um futuro próximo. Assim, mesmo que, teoricamente, a escola pública talvez tivesse maior facilidade de estar em sintonia com o que é indicado nos PCN em relação à educação para valores, acaba não tendo a possibilidade de pô-la em prática por falta de recursos, desejo ou agilidade. Ou seja, "embora a elaboração de determinada politica educacional seja considerada para 'fazer acontecer', não é condição suficiente" (CARVALHO, 2007, p. 2). 0 que se percebe é que, apesar de orientações e leis referentes à educação, há uma distinção concreta em relação aos resultados obtidos pela educação privada e a educação pública, que pode ser refletida no slogan:

Terminalidade legal para os nossos filhos e terminalidade real para o filho dos outros". Em consequência, o Estado Brasileiro não se revelou, ainda, capaz de democratizar o ensino, estando distante da organização de uma educação pública democrática de âmbito nacional (SAVIANI, 1997).

As escolas religiosas, por outro lado, não se atêm a nenhum dos modelos citados acima, pois trazem na bagagem princípios éticos embasados nas crenças e valores que as norteiam. Um exemplo é o Projeto Educativo Comum da Companhia de Jesus na América Latina (PEC), que define sua missão como:

Colaborar com a missão evangelizadora da Igreja, oferecendo uma formação integral de qualidade a meninos e meninas, jovens e adultos, à luz de uma concepção cristã da pessoa humana e da sociedade, através de comunidades educativas que vivam a sociedade justa e solidária que queremos construir [...] (CONFERÊNCIA..., 2005, p. 10).

Essa missão não abre mão, entretanto, da excelência acadêmica, como se pode perceber na definição dos processos educativos preconizados:

Os processos educativos são personalizados e apontam para a formação e capacitação para o trabalho, para a convivência democrática, para impulsionar a mudança e o desenvolvimento social e para a formação ética e religiosa. Orientam-se pela espiritualidade e pedagogia inacianas, encarnadas em uma instituição, para que todos cheguem a ser 'homens e mulheres para os demais' e 'com os demais', com excelência humana, alto nível acadêmico e capazes de liderança em seus ambientes (CONFERÊNCIA..., 2005, p. 10).

Ensaio: aval. pol. públ. Educ., Rio de Janeiro, v. 17, n. 64, p. 521-548, jul./set. 2009 
Assim, embora a realidade diária das escolas confessionais possa ainda mostrarse distante de seus projetos educativos, percebe-se que, pelo menos em termos de visão e intenção, estas se mostram mais próximas do que se espera de uma formação em valores e para a cidadania. Aproximam-se delas outras instituições privadas com características específicas e que atendem a apenas alguns segmentos da população e umas poucas escolas públicas de excelência. No todo, a pressão do mercado, representada pelos vestibulares e pelos resultados neles obtidos, acaba limitando o grau de liberdade com que se pode implantar um modelo de educação que vá além da questão acadêmica.

\section{Discurso e prática}

É nesse contexto que se desenvolve o discurso educacional que, como estudado anteriormente, é pautado em pesquisas e teorias desenvolvidas numa atmosfera de constantes transformações, devido às demandas atuais da sociedade. Desse modo, pode-se aqui afirmar que, em sua maioria, as práticas pedagógicas diferem do discurso, pois os agentes redatores de políticas e práticas estão distantes do espaço de aplicação das mesmas. A prática pedagógica ou do currículo, oriunda de uma esfera hierárquica piramidal, foge ao princípio de igualdade previsto na Constituição Federal. Poucos pensam em ações de muitos para múltiplos outros, sem efetivamente conhecê-los.

Na atualidade, embora já exista uma preocupação maior com o equilíbrio entre o discurso e a prática, ainda está presente a sistemática de que o Estado, junto a grupos técnicos, políticos e intelectuais e, até organizações privadas, estabeleça 0 que convém à sociedade. Essa leve mudança de postura ainda não oferece significativa voz ativa aos profissionais atuantes da educação, mas já mostra uma tentativa de mudança de paradigma.

Apesar de necessária, a mudança ainda esbarra nas perspectivas culturais de que os órgãos oficiais são os únicos responsáveis por delimitar diretrizes e fiscalizá-las. Além disso, deve-se levar em consideração que, em uma mudança de paradigma, o processo não é de eliminar as estratégias anteriores ou de desvalorizá-las, mas sim de agregar às mesmas novas estratégias ou modos de ação diferenciados.

0 discurso e a prática educacional deveriam caminhar juntos reconhecendo a escola como o espaço da inovação e efetivação da formação cidadã.

Nos PCN, o discurso diverge do que se entende como prática pedagógica, pois mantém a proposta de trabalhar em separado as várias áreas do conhecimento, inclusive o que se denomina como "temas transversais", mesmo reconhecendo-os, no modelo proposto, como estrutura básica da formação do cidadão. Logo, tentarse-á aqui estabelecer uma relação entre discurso e prática.

Ensaio: aval. pol. públ. Educ., Rio de Janeiro, v. 17, n. 64, p. 521-548, jul./set. 2009 
Para que a escola consiga evoluir junto às propostas das esferas oficiais é necessário que esta seja reconhecida como espaço de experiência e, mais que isso, que os sujeitos nela inseridos (professores, alunos, famílias, comunidade), sejam as ferramentas para a construção de um alicerce forte para possibilitar a desejada inovação. Mas esse alicerce só será efetivamente formado a partir do momento em que o interesse geral for o mesmo que o objetivo proposto, sem considerar as disputas de poder e os interesses econômicos. É preciso, portanto, haver transparência entre discurso e prática. E essa transparência deve refletir-se na elaboração do currículo.

A elaboração de um currículo envolve o levantamento de hipóteses, o estabelecimento de objetivos gerais e específicos que atendam às expectativas da sociedade, das famílias, dos profissionais, dos próprios alunos, as delimitações oficiais e, também, que integrem os aspectos dos domínios moral e cognitivo.

Para esta elaboração é necessário que a instituição de ensino, antes de olhar para o alunado, olhe para a estrutura que a constitui, avaliando-se, compreendendo-se, fortalecendo-se e se reconhecendo em projetos, propostas e ideais. É indispensável que a escola se exponha, sem fugir dos conflitos, sem atacá-los, tentando compreendê-los para, em seguida, superá-los.

Num momento seguinte à tomada de consciência particular da instituição, é necessária a exposição dessa identidade aos demais envolvidos e participantes, para que estes também se reconheçam ou não como integrantes do processo. A partir dessa identificação, é possivel que sejam estabelecidos novos conflitos, em busca de um novo equilibrio.

Assim surgirão, então, novas condições para que a equipe acadêmica, junto aos demais envolvidos, reconheça as condições pendentes para que sejam executadas ações efetivas, de modo a desenvolver um processo de formação com práticas integradoras (multidisciplinares, interdisciplinares, transdisciplinares [...]), envolvendo as "matérias acadêmicas" e os "temas transversais" em espaços e tempos comuns.

Com a aplicação desse tipo de prática será possível evitar os conflitos superficiais e melhor explorar valores, princípios, critérios morais e éticos das diferentes áreas do conhecimento integrando-as, sem que se sinta um "prejuízo" ao conteúdo acadêmico. Oferecem-se, pois, subsídios aos profissionais para gerir melhor os objetivos da instituição e da sociedade de maneira a atingir os propósitos constitucionais de formação de cidadãos plenos e conscientes.

Esses cidadãos, inseridos em uma sociedade cada vez mais globalizada, requerem, em uma perspectiva crítica e multicultural da educação, uma participação diferenciada dos profissionais da área de educação. Estes devem estar cientes das 
questões que a escola terá de enfrentar, referentes a multiculturalismo, raça, poder, identidade, significado de ética e trabalho e, mais do que isso, não devem opor-se ao desenvolvimento ou aceitação irrestrita de diferentes manifestações culturais, promovendo sempre o diálogo, de modo que o resultado final não seja pré-estabelecido, mas fruto de um processo em que a autocrítica também se faça presente. Podem, assim, ajudar a desenvolver, em si mesmos e junto aos alunos, uma abertura para que se combatam estereótipos e preconceitos e que leve à construção de uma postura inclusiva e de uma cultura de paz. Com isso, torna-se possivel transformar o espaço da aprendizagem em uma junção do conhecimento escolar (acadêmico) com os saberes que os individuos tragam consigo, tornando-o mais significativo para todos. Deste modo, ao mesmo tempo em que se busca oferecer oportunidades educacionais iguais para todos, visa-se à formação de novas gerações enriquecidas pela pluralidade étnica e cultural, sem que, com isso, deixem de acolher e considerar válidas as relações e valores reconhecidos como tais pela sociedade em geral.

\section{0 papel dos educadores}

0 envolvimento afetivo e emocional dos educadores parece ser uma condição indispensável para que, a partir da exposição de experiências particulares e juntamente com uma prática do diálogo e de relações democráticas, seja efetuada a análise de conjuntura e a geração de práticas não coercitivas na escola. Com isso, torna-se possível que exerçam a condição de pensadores reflexivos e "formadores" culturalmente comprometidos para o desenvolvimento pleno do cidadão melhorando, assim, a própria prática.

Para tanto, é necessário que os profissionais da área de educação sejam indivíduos solidamente formados, condição indispensável para a erradicação da ignorância ou do despreparo para a condução de um currículo educacional voltado para a formação em valores como caminho para uma sociedade efetivamente inclusiva. Tal modo de proceder ressalta a importância da prática docente como fruto de toda a sociedade, desenvolvida através dos diferentes meios e espaços sociais, com o propósito de estender o domínio da educação para os diversos contextos culturais e sociais, propiciando o pleno exercício da cidadania e não como uma reprodução mecânica ou pouco reflexiva de padrões pré-estabelecidos. Pelo fato de a educação moral, entretanto, ser mais aberta do que as disciplinas tradicionais - e isso, em verdade, aplica-se a todo trabalho que lide com temas transversais ou que seja realizado de forma inter ou transdisciplinar - parece que muitos profissionais não se sentem confiantes em relação à mesma.

Nesse sentido, é interessante uma breve apresentação e comentário dos resultados de uma pesquisa realizada junto a professores e estudantes de cursos de Ensino Médio de formação de professores no Brasil (LINS et al., 2007). Nesta, afirma-se que "os professores encontram dificuldades no que se refere ao ensino da Educação Moral para

Ensaio: aval. pol. públ. Educ., Rio de Janeiro, v. 17, n. 64, p. 521-548, jul./set. 2009 
alunos de todos os níveis escolares" (LINS et al., 2007, p. 257), e é realizada uma investigação sobre as causas desse fato. A pesquisa foi realizada com professores e alunos. Junto aos professores, foram realizadas entrevistas, que consistiam de cinco perguntas

[...] que objetivam detectar como os professores estavam formados nos conceitos de ética e moral, como viam e entendiam a proposta da LDB (BRASIL, 1996), de trabalhar a ética como tema transversal e quais estratégias adotavam para viver essa exigência legal (LINS et al., 2007, p. 259).

Quanto aos alunos, "as perguntas procuravam detectar como as possiveis influências da família, da comunidade onde vivem, das ambições, metas e interesses de vida pessoal e profissional influenciam na formação ética e moral" (LINS et al., 2007, p. 261).

Os resultados da pesquisa indicam a dificuldade que os professores têm de lidar com o tema da ética,

[...] tanto conceitualmente como do ponto de vista didático. Parece-nos que eles precisam ter um preparo um pouco mais adequado no que se refere à introdução de Temas Transversais simultaneamente aos conteúdos de suas disciplinas, inclusive quanto à Ética, apesar da instituição destes pelos PCN desde 1997 (LINS et al., 2007, p. 274).

Já os estudantes mostram-se interessados na formação em Educação Moral, "embora haja diferentes problemas concernentes à aprendizagem de ética" (LINS et al., 2007, p. 256).

Demonstraram não só interesse como um avanço na compreensão de conceitos e do papel da Educação Moral/Ética na vida de todas as pessoas. Principalmente entenderam a responsabilidade referente à exigência de um aprofundamento neste tema em função de seus futuros alunos (LINS et al., 2007, p. 274).

Para concluir, pode-se dizer que:

A educação em valores não é algo que se alcance simplesmente porque se acredita ou se deseja; é preciso encontrar meios para realizar de fato o que se imagina. No entanto, e com isso entramos no âmbito das consequências prováveis, o investimento que estamos propondo é rentável, porque atende a um imperativo: conseguir uma educação integral para todos. Mas é rentável também porque ajuda a criar um clima de convivência cidadã, que gera o capital social necessário para garantir o desenvolvimento, previne o fracasso escolar, ajuda a criar um clima de convivência e bem-estar nas escolas e contribui para formar cidadãos ativos de uma sociedade democrática (PUIG, 2007, p. 104).

Ensaio: aval. pol. públ. Educ., Rio de Janeiro, v. 17, n. 64, p. 521-548, jul./set. 2009 


\section{Educação para valores e currículo}

Para a elaboração de uma base curricular é importante lembrar que, anterior à Escola, o conhecimento se dava através da oralidade, ferramenta utilizada até hoje na comunicação de conteúdos formais e informais. Com o passar do tempo, a humanidade desenvolveu teorias e práticas para educar, ensinar, compreender, analisar e

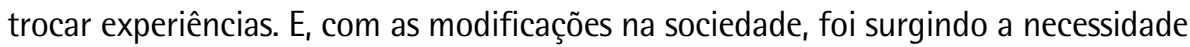
de formalizar o processo de ensino-aprendizagem, efetivando um sistema de ensinar e aprender a ler, escrever e interpretar, que se faz presente até a atualidade. No currículo para valores não é diferente, os seres humanos necessitam "ler", "escrever" e "interpretar" as demandas da sociedade, ao mesmo tempo em que têm que "dar conta" dos mínimos de justiça em busca dos máximos de felicidade.

A criação e sedimentação do currículo ocorreram para atender às necessidades da sociedade de definir o quê, quando, como e para quem ensinar. Por outro lado, as transformações sociais levaram à necessidade de alterações e flexibilização do mesmo, levando-o a afastar-se (ou, pelo menos, recomendando que se afastasse) de uma forma fixa e padronizada. Os PCN confirmam essa necessidade ao afirmarem que "incorporam essa tendência e a incluem no currículo de forma a compor um conjunto articulado e aberto a novos temas. [...] 0 currículo ganha em flexibilidade e abertura" (PARÂMETROS..., 2000, p. 29).

Será desenvolvida a seguir, a partir do referencial teórico, uma proposta de currículo em que os indivíduos não apenas sejam formalmente apresentados à temática transversal da ética para a conscientização das ações cotidianas e a formação de cidadãos, mas que isso seja feito a partir de suas experiências e de um diagnóstico do que lhes é mais necessário nesse sentido. Embora reconhecendo que a educação para valores pode ocorrer, conforme Puig (2007, p. 85), pelas "vias educativas do enraizamento e da abertura para os demais", pela "via interpessoal" e pela "via institucional", além de poder existir pela "via curricular", optou-se por trabalhar a partir desta última. Este "modelo de formação em valores se refere às tarefas de aula destinadas a trabalhar valores, embora sua localização temporal no currículo possa variar" (PUIG, 2007, p. 90). E, nele: "As tarefas curriculares colocam em jogo três grandes blocos de conteúdo: as questões pessoais ou socialmente relevantes, as disposições que constituem a inteligência moral e, por último, alguns elementos básicos da cultura moral de uma sociedade" (PUIG, 2007, p. 90).

Serão dadas, pois, as recomendações para o desenvolvimento básico de um currículo que contemple as questões fundamentais de uma educação para valores e que leve a um ambiente educacional e social inclusivo, contemplando pontos de diagnose de necessidades e como incluir o resultado dessa diagnose no dia a dia. Para tal, pretende-se seguir o modelo de fluxo de trabalho e planejamento apresentado na Figura 1.

Ensaio: aval. pol. públ. Educ., Rio de Janeiro, v. 17, n. 64, p. 521-548, jul./set. 2009 


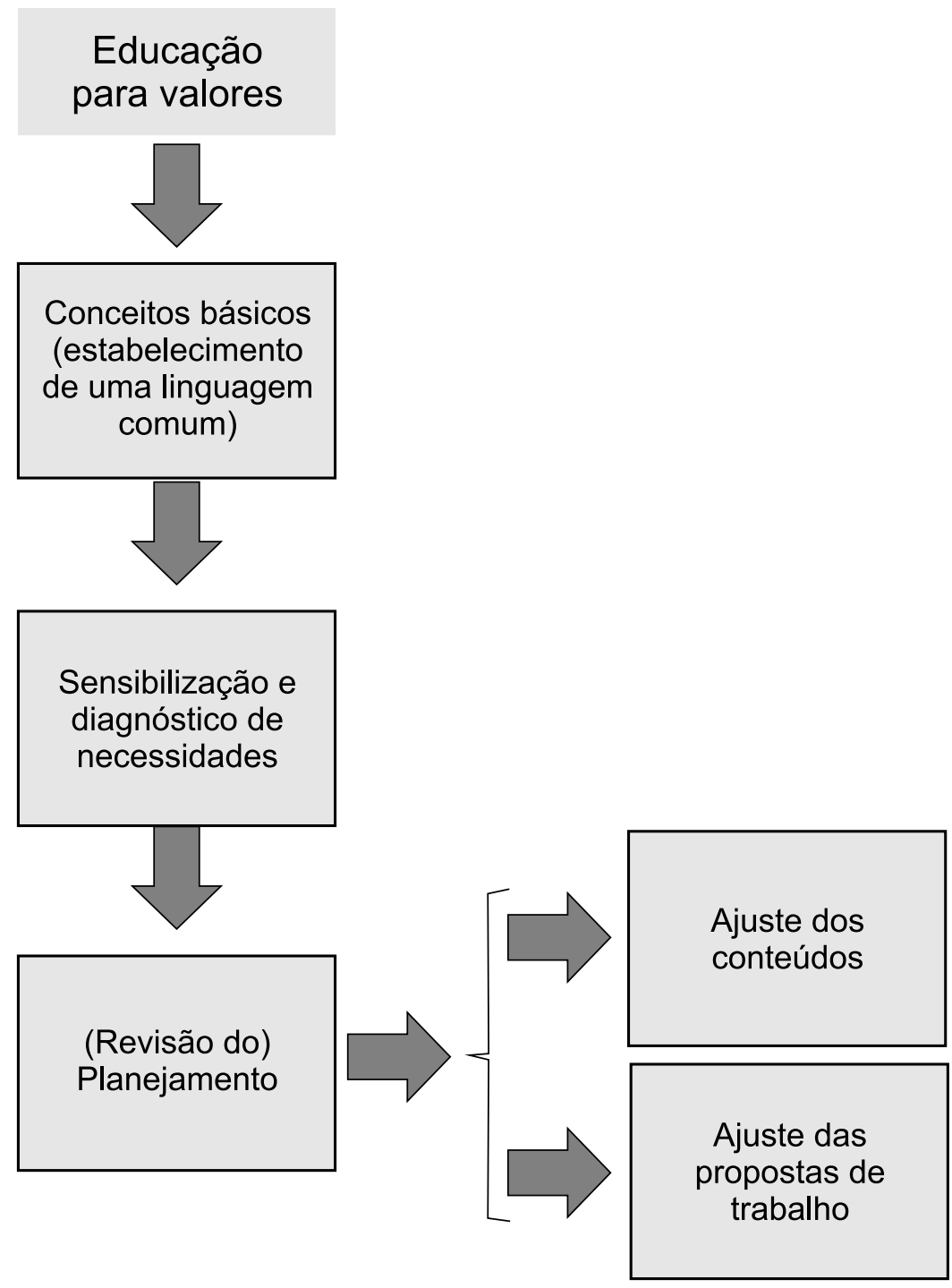

Figura 1 - Educação para Valores: fluxo de trabalho.

Fonte: Os autores (2008).

Este fluxo é apresentado em forma aberta por simplicidade de representação, embora o processo de avaliação e planejamento de atividades pedagógicas seja cíclico e contínuo. É, também, aplicável a qualquer modelo escolar (Tabela 1) em que haja interface entre a vertente acadêmica e a vertente moral da educação. Cada um dos blocos do diagrama da Figura 1 será analisado separadamente, indicando-se as formas de concatenação possiveis.

Ensaio: aval. pol. públ. Educ., Rio de Janeiro, v. 17, n. 64, p. 521-548, jul./set. 2009 


\section{Conceitos básicos}

0 objetivo do trabalho com os conceitos básicos de uma educação para valores é o estabelecimento de uma linguagem comum entre professores e alunos e, respeitadas as especificidades de cada faixa etária ou de desenvolvimento moral, deveria tratar do conteúdo mínimo já citado no corpo deste trabalho: igualdade e justiça; tolerância e respeito mútuo; diálogo; liberdade; solidariedade. Este conteúdo serviria de substrato para a construção da autonomia, etapa mais elevada conforme Piaget, refletido nos níveis mais altos dos estágios de juízo moral descritos por Kohlberg (Tabela 2). 0 desenvolvimento dos conceitos básicos, por sua vez, pode ocorrer através de dois modos distintos:

- Explicitamente, quer em uma disciplina específica - história, geografia, sociologia, filosofia, ensino religioso, por exemplo -, quer sob a forma de temas transversais, como, aliás, é preconizado nos PCN;

- Implicitamente, quer sob a forma de temas transversais, quer através de dinâmicas, confrontação com dilemas (morais ou não) e atividades lúdicas que podem ser concomitantes à sensibilização dos alunos para o tema desejado ou diagnóstico das necessidades de trabalho.

Entende-se que o mais desejável é um envolvimento prévio dos alunos através de atividades que permitam que eles tragam para o grupo aquilo que já vivem no ambiente social no qual estão inseridos - incluindo o familiar - para que, a partir daí, consigam associar essa vivência aos conceitos a serem trabalhados.

\section{Sensibilização e diagnóstico de necessidades}

Se a primeira etapa do processo descrito, mesmo que desenvolvida através da vivência de experiências, é voltada para o conhecimento, a segunda é voltada explicitamente para a sociedade, buscando chamar a atenção sobre modos de, a partir da realidade existente, levar ao desenvolvimento de atitudes e ações para que se conquiste a melhoria da qualidade de vida na comunidade. Trata-se de trabalhar questões morais com uma perspectiva transformadora, que pode partir tanto da dimensão acadêmica como da dimensão dos valores para, então, redimensionar as ações morais. Deste modo, os processos educativos envolvem conteúdos conceituais, procedimentais e atitudinais. 0 ideal é que esta etapa ocorra em um ambiente de livre expressão, sem uma perspectiva de avaliação formal, em que os participantes possam manifestar-se espontaneamente, preferencialmente tendo como ponto de partida uma situação do cotidiano dos envolvidos.

É importante que a atividade seja planejada com objetivos claramente definidos, de modo a não tornar difícil a identificação de necessidades, bem como sejam definidos momentos que tornem fácil o diagnóstico das situações envolvidas. Os educadores envolvidos na atividade devem ser capazes de ouvir e observar atentamente, para coletar os dados necessários à etapa seguinte.

Ensaio: aval. pol. públ. Educ., Rio de Janeiro, v. 17, n. 64, p. 521-548, jul./set. 2009 


\section{Planejamento}

A partir das etapas anteriores, é possível efetivamente planejar as etapas seguintes ou rever o planejamento já efetuado, tanto em termos de abrangência como de adequação. 0 trabalho referente à educação em valores pode ser ajustado quanto aos conteúdos ou quanto às propostas de trabalho dos mesmos.

- Ajuste dos conteúdos: em função dos resultados já obtidos, pode-se perceber a necessidade de aprofundar conceitos específicos, relação entre conceitos ou mesmo sua aplicação a situações do cotidiano dos alunos.

- Ajuste das propostas de trabalho: de maneira similar, pode ser necessário rever o modo de trabalhar as questões de valores junto aos alunos, quer em relação à mescla ou proporção entre apresentação acadêmica e atividades de sensibilização, quer em relação à frequência ou espaço de realização do trabalho.

Trata-se, na verdade, da realização de um ciclo contínuo de aplicação, diagnóstico, avaliação e atualização das propostas de trabalho sobre a questão de valores, ciclo este que, aliás, deveria ser costumeiro em relação a todas as atividades referentes à aprendizagem escolar.

Parece, também, que, independente do modo escolhido para a realização do trabalho com valores, o ideal seria integrar o planejamento curricular por meio de docência compartilhada, em que professores que hoje trabalham isoladamente, sem se comunicarem, identificassem competências e conteúdos comuns em seus programas, realizando um planejamento conjunto e um projeto de responsabilidade também conjunta. Este projeto incluiria uma forma de atuação cooperativa, com aulas, materiais, tarefas e avaliações comuns, o que vai de encontro às tendências culturais atuais de trabalho compartilhado e cognição cooperativa. Esta forma de trabalho responde, ainda, às necessidades de uma grade curricular saturada em que, devido à pressão de resultados, nenhum docente quer abrir mão de tempos de aula, mesmo diante da exigência legal de inclusão de novas matérias, como a filosofia e a sociologia. Para quebrar o paradigma vigente, porém, é preciso haver preparo, planejamento, coragem e investimento.

\section{Considerações finais}

Em uma sociedade cada vez mais plural, colocar os meios para que se estabeleça uma cultura inclusiva e de paz é fundamental. Embora os exemplos da família e da sociedade sejam primordiais para a organização dos grupos sociais e para a definição do modelo de convivência que será estabelecido, entende-se que é necessário analisar e explicitar as bases desse modelo, ou seja, sobre que valores ele é construído. A própria pluralidade dificulta um consenso sobre quais valores fariam parte de um "mínimo exigível" para todos.

Ensaio: aval. pol. públ. Educ., Rio de Janeiro, v. 17, n. 64, p. 521-548, jul./set. 2009 
Uma vez que a escola tem, historicamente, papel primordial para a reprodução e sedimentação de um modelo social, ela, mesmo não sendo a responsável principal, e muito menos única, para a formação ética, tem uma função importante nesse sentido, em conjunto com a família e a sociedade como um todo. Nota-se, entretanto, que há duas mudanças, quase contraditórias entre si, que dificultam uma atualização desse papel:

- Por um lado, a relutância por parte da escola em abandonar o paradigma tradicional - quer por convicção, quer por medo ou por não saber como encaminhar um processo de mudança - sobretudo na sociedade americana e brasileira, em que ela é transmissora, essencialmente, de saberes acadêmicos, preparando os alunos para o sucesso no vestibular e para o "mercado";

- Por outro lado, uma nova estrutura de família, em que os pais transferem cada vez mais para a escola responsabilidades e expectativas referentes à educação moral, antes assumidas por eles.

Essa situação reflete-se em uma estrutura curricular que não favorece uma integração entre o ensino acadêmico e o moral, mesmo em instituições, como as escolas confessionais, que afirmam privilegiar a formação integral. Como visto nos exemplos apresentados, mesmo quando os currículos contemplam espaços e atividades específicos para a formação moral, não há nem um planejamento integrado, nem estruturas que permitam uma revisão do planejamento de modo a incluir, no dia a dia escolar, questões específicas identificadas nessas atividades. Há, ainda, visões diferentes sobre como trabalhar valores na escola: através de temas transversais ou de conteúdos. 0 que parece é que, conforme 0 modelo sugerido na Figura 1, o mais adequado é uma conjugação de ambos, com a realização de um processo constante e cíclico de diagnóstico e adaptação curricular a partir do mesmo.

É importante lembrar, também, que a questão da capacitação dos profissionais de educação é, ainda hoje, precária, não lhes oferecendo formação e apoio para que realizem uma tarefa cada vez mais distante do senso comum, do previsível e do tradicional. Tanto por questões estruturais como de custo, as instituições de ensino não oferecem espaços de planejamento e discussão que contemplem uma realidade a cada dia mais complexa. Ademais, educar para valores não é apenas conhecer conteúdos e tentar transmiti-los aos alunos, mas estabelecer uma prática coerente e democrática na escola.

Essa prática parece essencial para a definição do papel dos seres humanos na sociedade e a valorização dos mesmos. Nesse sentido, a educação moral e em valores possui um papel importante na percepção de que as diferenças são naturais e de que se devem respeitar todos e cada um em suas especificidades, como construtores de uma cultura

Ensaio: aval. pol. públ. Educ., Rio de Janeiro, v. 17, n. 64, p. 521-548, jul./set. 2009 
plural e de paz. Nas palavras de Jacques Delors (1996 apud CAMPBELL, 2002, p. 33) no relatório da International Commission on Education for the $21^{\text {st }}$ Century:

Ao ver-se confrontada com os muitos desafios que o futuro guarda para ela, a humanidade vê na educação um valor indispensável à sua tentativa de atingir os ideais de paz, liberdade e justiça. Ao concluir seus trabalhos, a Comissão afirma sua crença de que a educação tenha um papel fundamental a desempenhar no desenvolvimento pessoal e social. A Comissão não vê a educação como uma cura milagrosa ou como uma fórmula mágica para abrir as portas de um mundo onde todos os ideais serão alcançados, mas sim como um dos principais meios que temos à nossa disposição para favorecer a criação de uma forma mais profunda e mais harmônica de desenvolvimento humano e, assim, reduzir a pobreza, a exclusão, a ignorância, a opressão e a guerra.

\section{Referências}

ANDRADE, M. Ética mínima e educação plural: em busca de fundamentos éticofilosóficos para uma educação intercultural. In: CANDAU, V. M. (Org.). Educação intercultural e cotidiano escolar. Rio de Janeiro: 7letras, 2006.

ARAÚJO, U. F. A construção social e psicológica dos valores. In: ARAÚJO, U.; PUIG, J. M.; ARANTES, V. A. (Org.). Educação e valores. São Paulo: Summus, 2007.

BERTICELLI, I. A. Currículo: tendências e filosofia. In: BERTICELLI, I. A. O currículo nos lineares do contemporâneo. Rio de Janeiro: DPCtA, 2005.

BETTO, Frei. Ensino religioso nas escolas. Correio Braziliense, Brasília, DF, 23 mar. 2007. Disponivel em: <http://clipping.planejamento.gov.br/ Noticias.asp?NOTCod=344295>. Acesso em: 20 ago. 2008.

CALDANA, R. H. L. A criança e sua educação na família no início do século: autoridade, limites e cotidiano. Temas em Psicologia, Ribeirão Preto, SP, v. 6, n. 2 , p. 87-103, 1998.

CAMPBELL, J (Org.). Construindo um futuro comum: educando para a integração na diversidade. Brasilia, DF: UNESCO, 2002. 
CANDAU, V. M. Educação em direitos humanos no Brasil: realidade e perspectivas. In: CANDAU, V. M.; SACAVINO, S. (Org.). Educar em direitos humanos. construir democracia. 2. ed. Rio de Janeiro: DPEA, 2003.

CARVALHO, R. E. Das políticas de educação especial às políticas de orientação inclusiva. In: SEMINÁRIO NACIONAL DE PESOUISA E EDUCAÇÃO ESPECIAL: diálogo e pluralidade, 3., 2007, Marilia. Trabalhos apresentados... Marilia, SP: ABPEE, 2007.

CONFERÊNCIA DE PROVINCIAIS JESUITAS DA AMÉRICA LATINA. Projeto educativo comum da Companhia de Jesus na América Latina. Rio de Janeiro: Daugraf, 2005.

DELORS, J. (Org.). Learning: the treasure within: report of the International Commission on Education for the $21^{\text {st }}$ Century. In: CAMPBELL, J. (Org.). Construindo um futuro comum: educando para a integração na diversidade. Brasilia, DF: UNESCO, 2002.

DIAZ-AGUADO, M. J.; MEDRANO, C. Construção moral e educação: uma aproximação construtivista para trabalhar os conteúdos transversais. Bauru; SP: EDUSC, 1999.

JAPIASSÚ, H.; MARONDES, D. Dicionário básico de filosofia. 3. Ed. rev. amp. Rio de Janeiro: Jorge Zahar, 1996.

LINS, M. J. S. C. et al. Avaliação da aprendizagem de ética em curso de formação de professores de Ensino Fundamental. Ensaio: avaliação e políticas públicas em educação. Rio de Janeiro, v. 15, n. 55, p. 255-276, abr./jun. 2007.

POWER, C. N. A resposta da UNESCO ao desafio de criar unidade na diversidade. In: CAMPBELL, Jack (Org.). Construindo um futuro comum: educando para a integração na diversidade. Brasília, DF: UNESCO, 2002.

PUIG, J. M. Aprender a viver. In: ARAÚJO, U.; PUIG, J. M.; ARANTES, V. A. (Org.). Educação e valores. São Paulo: Summus, 2007.

SAVIANI, D. A educação como questão nacional. In: A nova lei da educação: trajetórias, limites e perspectivas. Campinas, SP: Autores Associados, 1997.

PARÂMETROS Curriculares Nacionais: apresentação dos temas transversais: ética. Brasilia, DF: MEC, Secretaria de Educação Fundamental, 2000.

PARÂMETROS Curriculares Nacionais: introdução. Brasilia, DF: MEC, Secretaria de Educação Fundamental, 1997. 
SETTON, M. G. J. Família, escola e mídia: um campo com novas configurações. Educação e Pesquisa, São Paulo, v. 28, n. 1, p. 107-116, jan./jun. 2002.

STENGEL, B. S.; TOM, A. R. Moral matters. five ways to develop the moral life of schools. New York: Teachers College Press, 2006.

Recebido em: 20/02/2009

Aceito para publicação em: 28/06/2009 